\title{
Weather conditions associated with autumn migration by mule deer in Wyoming
}

Chadwick Rittenhouse, Tony W Mong, Thomas Hart

Maintaining ecological integrity necessitates a proactive approach of identifying and acquiring lands to conserve unfragmented landscapes, as well as evaluating existing mitigation strategies to increase connectivity in fragmented landscapes. The increased use of highway underpasses and overpasses to restore connectivity for wildlife species offers clear conservation benefits, yet also presents a unique opportunity to understand how weather conditions may impact movement of wildlife species. We used remote camera observations $(19,480)$ from an existing wildlife highway underpass in Wyoming and daily meteorological observations to quantify weather conditions associated with autumn migration of mule deer in 2009 and 2010. We identified minimal daily temperature and snow depth as proximate cues associated with mule deer migration to winter range. These weather cues were consistent across does and bucks, but differed slightly by year. Additionally, extreme early season snow depth or cold temperature events appear to be associated with onset of migration. This information will assist wildlife managers and transportation officials as they plan future projects to maintain and enhance migration routes for mule deer. 
2 Corresponding Author: Chadwick D. Rittenhouse, Visiting Assistant Professor; Wildlife and

3 Fisheries Conservation Center, Department of Natural Resources and the Environment,

4 University of Connecticut, 1376 Storrs Rd. Unit 4087, Storrs, CT 06269-4087;

5 chadwick.rittenhouse@uconn.edu; (860) 486-0335

6 Tony W. Mong, Senior Wildlife Biologist; Wyoming Game and Fish Department, P.O. Box

7 116, Savery, WY 82332; tony.mong@wyo.gov; (307) 383-2042

8 Thomas Hart, Wildlife and Fisheries Specialist; Environmental Services Section, Wyoming

9 Department of Transportation, 5300 Bishop Blvd., Cheyenne, WY 82009; thomas.hart@wyo.gov;

$10 \quad(307) 777-4495$ 


\section{Introduction}

Maintaining ecological integrity necessitates a proactive approach of identifying threats to species, communities, and the ecological processes that sustain them. For mule deer (Odocoileus hemionus), a culturally and economically important species (Copeland et al 2014), habitat fragmentation can present barriers to migration, alter migration routes, or increase mortality through deer-vehicle collisions (Sawyer et al. 2012).

Highway underpasses have restored connectivity for mule deer in fragmented landscapes (Reed 1975, Ng et al 2004, Clevenger and Waltho 2005, Braden et al. 2008, Gagnon et al. 2011). The unique structure of highway underpasses and associated fencing, when coupled with remote cameras and weather observations, presents an opportunity to gain substantial information on population age and sex structure (Ikeda et al. 2013), abundance (Rowcliffe et al. 2008), and proximate cues associated with migratory movement. Yet, the relationships between migratory movements and weather conditions are understudied, despite the importance of this for informing policy and adaptive management decisions regarding connectivity in the context of a changing climate.

Our objective was to identify weather conditions associated with autumn migration by mule deer in Wyoming. Our central hypothesis is that entering the winter range too early comes at the expense of reproductive output and survival of young mule deer. Our basis for this hypothesis arises from known nutritional limitations and energetic costs of winter to mule deer (Bartmann et al. 1992, Poole and Mowat 2005, Bishop et al. 2009); premature entry to the winter grounds presumably provides no advantage to adults or offspring. Based on this hypothesis, we predict that mule deer movements through the underpass will be associated with timing of snowfall events and snow depth that cover forage on summer grounds. Identification of the 
34 specific cue(s) used by mule deer during migration may allow managers to anticipate changes in

35 migration based on weather conditions.

\section{Methods}

\section{Study site and camera set-up}

We collected animal migration data using a trail camera set up to monitor a highway underpass on Hwy. 789 approximately 8 km north of Baggs, Wyoming (Figure 1). The underpass was installed in 2009 and equipped with a RECONYX Hyperfire (TM) camera mounted approximately 1.5 meter high centered within the underpass. The camera was pointed towards the direction animals were migrating from, so during autumn the camera was pointed east. Camera settings included a distance from camera to subjects of $18.2 \mathrm{~m}$ with a $1 / 5$ second trigger speed; three photos recorded when motion was detected, and photo resolution of 1080P High Definition or 3.1 Mega-pixels. Cameras remained active throughout the year; however, during autumn migrations by mule deer the images were downloaded more frequently. Autumn migration dates were November 1 to December 31 of each year. The Wyoming Game and Fish Department approved this research (Permit \#791).

The study site was defined by the Baggs Mule Deer Herd Unit, which encompasses 1,092

$\mathrm{km}^{2}$ south of I-80 in southern Carbon County (Figure 1). This area supports a variety of vegetation types, but is generally characterized by rolling topography, prominent ridges, and dry canyons dominated by sagebrush (Artemisia sp.), black greasewood (Sacrobatus vermiculatus), Utah juniper (Juniperus osteosperma), and other mixed-shrub (Purshia tridentata, Prunus virginiana, Amelanchier alnifolia, Chrysothamnus sp., Cercocarpus sp.). Elevations range from 1,920 to $2,530 \mathrm{~m}$.

Population age and sex structure 
We used images taken by the camera to count and assign age class (fawn, yearling, adult) and sex to all deer passing through the underpass during autumn migrations 2009 and 2010. Does and fawns migrated together, as did adult and yearling bucks. Therefore, we tallied does separate from fawn, yearling buck, and adult classes. While most deer moved through the underpass one way, in some instances multiple images were obtained of the same individuals due to the threeimage sequence provided by the camera. When this occurred we used group size, group composition, and size of individuals to count unique individuals only.

Common indices used by wildlife managers to monitor population sex and age structure include: ratio of adult doe per fawn, ratio of adult doe per yearling buck, and ratio of adult doe per adult buck. We quantified those ratios for fall migration of each year and provide SE and $95 \%$ CI. Association of migratory movements with weather conditions

We obtained meteorological records from the Battle Creek weather station $(31 \mathrm{~km}$ from underpass, Natural Resources Conservation Service Snotel Site number 317, 41 deg; 3 min N, $107 \mathrm{deg} ; 16 \mathrm{~min} \mathrm{~W})$. The meteorological records consisted of daily records of maximum air temperature $\left({ }^{\circ} \mathrm{C}\right)$, minimum air temperature $\left({ }^{\circ} \mathrm{C}\right)$, average air temperature $\left({ }^{\circ} \mathrm{C}\right)$, precipitation accumulation (in), snow water equivalent (in), and snow depth (in). From those weather observations, we calculated one additional metric: snow event. Snow event had a value of 1 if snow fell on that day. If no snow fell on that day we assigned a value of 0 to snow event. Preliminary analyses indicated high correlations $(\mathrm{R}>0.50)$ among all weather variables, so we proceeded with models containing each weather variable separately. Preliminary analyses also indicated that weather observations from the previous day were better predictors of daily migration counts than same day observations because they accounted for the lag between a 
weather event at higher elevation and deer arrival at the underpass. Therefore all weather conditions except snow depth reflected the previous day's weather.

To identify weather conditions associated with autumn migration by mule deer, we modeled counts of does and bucks (yearling and adult combined) as a function of weather variables. The counts were specified as the response variable in separate models of minimum air temperature, maximum air temperature, precipitation amount, snowfall event, and snow depth as independent variables. For each model we included each independent weather variable and an interaction term with day of the migration season, with day 1 corresponding to 17 October 2009 and 8 October 2010. We also examined a model that consisted of all independent variables and their interactions with day of migration season.

We used negative binomial regression models to handle overdispersed count data with 0 observations. We used Akaike's information criterion (AIC) to rank models and Akaike weights $\left(w_{i}\right)$ to determine which model associating migration with weather conditions had the strongest support (Burnham and Anderson 2002). We fitted all models with the glm.nb function in the R language and environment for statistical analyses (version 2.15.2) (R Core Development Team 2012).

\section{Results}

Analysis of 19,480 images acquired during fall migration 2009 and fall migration 2010 documented 6,628 counts of mule deer using the underpass (Table 1). The population age and sex structure was consistent across the two years with a mean of 61 fawns, 8 yearling bucks, and 14 adult bucks per 100 does (Table 1).

Model-selection results indicated minimum air temperature and snow depth were the best proximate cues associated with autumn migration. In 2009, minimum air temperature of the 
103 previous day was the most supported model for does and bucks, with maximum air temperature

104 of the previous day competing with the most supported model for bucks only (Table 2). In 2010,

105 snow depth was the most supported model for does and bucks with no competing models for

106 either sex. Higher counts of deer occurred on days with lower minimum temperatures in 2009

107 and on days with greater snow depth in 2010 (Table 3). Bucks and does responded similarly to

108 weather conditions within and across years despite migrating in separate groups.

109 We used coefficients from the top fitted models to predict use of the highway underpass

110 under the range of weather conditions observed in 2009 and 2010 (Figure 2). Early, extreme

111 minimum air temperatures and snow depths had the highest predicted counts of does and bucks.

112 Based on these model predictions, thresholds for onset of migration were minimum air

113 temperature of 0 to $-5^{\circ} \mathrm{C}$ or snow depth exceeding $25.4 \mathrm{~cm}$.

\section{Discussion}

115 Wildlife underpasses and overpasses are used throughout western North America to

116 restore connectivity for migratory and large-ranging species. We demonstrated that monitoring

117 wildlife underpasses provides important demographic and movement information, which when

118 coupled with weather observations can be used to understand connectivity and migratory

119 dynamics associated with weather conditions. The association between weather conditions and

120 counts of deer using the underpass was consistent with our expectation. Specifically, we

121 identified minimal daily temperature and snow depth as proximate cues used by mule deer

122 during migration to winter range. These weather cues were consistent across does and bucks, but

123 differed slightly by year. Additionally, extreme early season snow depth exceeding $25.4 \mathrm{~cm}$ or

124 minimum air temperature of 0 to $-5^{\circ} \mathrm{C}$ may be associated with onset of migration. 
Our results using a single camera trap were consistent with radio-telemetry studies of

126

127

128

129

130

131

132

133

134

135

136

137

138

139

140

141

142

143

144

145

146

147

mule deer migration. Previous studies identified decreasing daily temperature, increasing snow

depth, and senescing vegetation as factors associated with autumn migration from high-elevation

summer ranges to low-elevation winter ranges (Garrott et al. 1987, Nicholson et al. 1997,

Monteith et al. 2011). However, the specific relationships varied by vegetation type, elevation,

and climate. In the sagebrush-steppe ecosystem of the Sierra Nevada Mountains in California,

the onset of migration coincided with average daily temperature $<5 \mathrm{C}$ and snow depth $>0 \mathrm{~cm}$

(Monteith et al. 2011). In a pinyon pine-Utah juniper shrubland complex in northwestern

Colorado, mule deer migration occurred with average daily temperature $>0 \mathrm{C}$ and no snow depth

(Garrott et al. 1987). In the San Bernardino Mountains of southern California, mule deer

exhibited partial migration in response to snow cover (Nicholson et al. 1997).

Installation of under and overpasses are effective in reducing deer-vehicle collisions

(Clevenger et al 2001). However, under and overpasses may be cost prohibitive and thus

alternative methods of migration route protection may need to be developed. In this situation,

variability in the number of mule deer entering the winter range poses substantial challenges to

managing mule deer-human interactions. One alternative is to use weather information to better

time the use of temporary signage on roads crossed by migration routes. Temporary signage

could indicate speed reduction or simply increase awareness that migration movements are more likely on days with suitable weather conditions.

In addition to providing information that could be used to more effectively manage

migration route-road crossings, acquiring images of deer using underpasses and overpasses may

also increase the efficiency of monitoring efforts by state agencies. Long-term population

monitoring for setting harvest regulations typically uses aerial surveys of summer grounds 
148 conducted just after the hunting season and prior to migration to wintering grounds. A concern

149 with post-hunt aerial surveys is the potential to miss animals or have a biased sample if some

150 classes of animals migrate prior to the survey. In these situations, underpass and overpass data

151 may complement post-hunt aerial surveys by providing additional sampling periods during

152 spring and fall migration. Having multiple sampling periods would enable within-year estimates

153 of survival and recruitment as opposed to single, annual estimate.

154 Conclusions

Underpass and overpass data coupled with meteorological observations can be used to understand the relationship between weather and migration. With short-term data, we identified minimum daily temperature and snow depth as proximate cues associated with mule deer migration to winter range in Wyoming. Long-term data will provide information on migration dynamics, including whether the onset, duration, or magnitude of migration co-changes with weather. Long-term data may also reveal the role of weather in partial migration, cessation of migration or changes in route location over time.

Acknowledgments

We thank Jerod Merkle, Stuart Pimm, and Grant Harris for comments that improved the manuscript.

\section{References}

Bartmann, R.M., G.C. White, and L.H. Carpenter. 1992. Compensatory mortality in a Colorado mule deer population. Wildlife Monographs 121:1-39. enhanced nutrition on mule deer population rate of change. Wildlife Monographs 172:1-28. 
170 Braden, A. W., R. R. Lopez, C. W. Roberts, N. J. Silvy, C. B. Owen and P. A. Frank. 2008.

171 Florida Key deer Odocoileus virginianus clavium underpass use and movements along a

172 highway corridor. Wildlife Biology 14:155-163.

173 Burnham, K.P., and D.R. Anderson. 2002. Model selection and multimodel inference: a practical

174 information-theoretic approach. Second edition. Springer-Verlag, New York, New York, 175 USA.

176 Clevenger, A.P., B. Chruszez, and K.E. Gunson. 2001. Highway mitigation fencing reduces 177 wildlife-vehicle collisions. Wildlife Society Bulletin 29: 646-653.

178 Clevenger, A.P., and N. Waltho. 2005. Performance indices to identify attributes of highway 179 crossing structures facilitating movement of large mammals. Biological Conservation $180 \quad 121: 4453-464$.

181 Copeland, H.E., H. Sawyer, K.L. Monteith, D.E. Naugle, A. Powewicz, N. Graf, and M.J. 182 Kauffman. 2014. Conserving migratory mule deer through the umbrella of sage-grouse. $183 \quad$ Ecosphere 5:art117. http://dx.doi.org/10.1890/ES14-00186.1

184 Gagnon, J.W., N.L. Dodd, K.S. Ogren, and R.E. Schweinsburg. 2011. Factors associated with 185 use of wildlife underpasses and the importance of long-term monitoring. Journal of Wildlife $186 \quad$ Management 75:1477-1487.

187 Garrott, R.A., G.C. White, R.M. Bartmann, L.H. Carpenter, and A.W. Alldredge. 1987.

188 Movements of female mule deer in northwest Colorado. Journal of Wildlife Management $18951: 634-643$.

190 Ikeda, T., H. Takahashi, T. Yoshida, H. Igota, and K. Kaji. 2013. Evaluation of camera trap 191 surveys for estimation of sika deer herd composition. Mammal Study 38:29-33. 
192 Monteith, K.L., V.C. Bleich, T.R. Stephenson, B.M. Pierce, M.M. Conner, R.W. Klaver, and

193 R.T. Bowyer. 2011. Timing of seasonal migration in mule deer: effects of climate, plant

194 phenology, and life-history characteristics. Ecosphere 2(4):art47. doi:10.1890/ES10-00096.1.

195 Ng, S.J., J.W. Dole, R.M. Sauvajot, S.P.D. Riley, and T.J. Valone. 2004. Use of highway

196 undercrossings by wildlife in southern California. Biological Conservation 115:499-507.

197 Nicholson, M.C., R.T. Bowyer, and J.G. Kie. 1997. Habitat selection and survival of mule deer:

198 tradeoffs associated with migration. Journal of Mammalogy 78:483-504.

199 Poole, K.G., and G. Mowat. 2005. Winter habitat relationships of deer and elk in the temperate

200 interior mountains of British Columbia. Wildlife Society Bulletin 33:1288-1302.

201 R Core Development Team. 2012. R: a language and Environment for Statistical Computing. R

202 Foundation for Statistical Computing, Vienna.

203 Reed, D.F., T.N. Woodward, and T.M. Pojar. 1975. Behavioral response of mule deer to a

204 highway underpass. Journal of Wildlife Management 39:361-367.

205 Rowcliffe, J.M., J. Field, S.T. Turvey, and C. Carbone. 2008. Estimating animal density using

206 camera traps without the need for individual recognition. Journal of Applied Ecology 45:

$207 \quad 1228-1236$.

208 Sawyer, H., C. LeBeau and T. Hart. 2012. Mitigating roadway impacts to migratory mule deer209 a case study with underpasses and continuous fencing. Wildlife Society Bulletin 36:492-498. 


\section{Table $\mathbf{1}$ (on next page)}

Counts of mule deer by age and sex classes

Age and sex counts and ratios of mule deer in the Baggs District of Wyoming observed from a camera trap fixed to a highway underpass during autumn migration of 2009 and 2010. 


\begin{tabular}{lllllll}
\hline \multirow{2}{*}{ Year } & Sex-age class & $\mathrm{N}$ & $\begin{array}{l}\text { Ratio of does per } \\
\text { sex-age class }\end{array}$ & SE & $-95 \% \mathrm{CI}$ & $+95 \%$ CI \\
\hline 2009 & Does & 1205 & & & & \\
& Fawns & 754 & 1.60 & 0.07 & 1.45 & 1.74 \\
& Yearling bucks & 81 & 14.88 & 1.71 & 11.53 & 18.22 \\
\multirow{2}{*}{2010} & Adult bucks & 170 & 7.09 & 0.58 & 5.95 & 8.23 \\
& Does & 2401 & & & & \\
& Fawns & 1441 & 1.67 & 0.06 & 1.56 & 1.78 \\
& Yearling bucks & 228 & 10.53 & 0.73 & 9.10 & 11.96 \\
& Adult bucks & 315 & 7.62 & 0.46 & 6.73 & 8.52 \\
\hline
\end{tabular}

2 
Table 2 (on next page)

AIC ranks for models associating weather and mule deer migration

Ranked empirical support for models examining how weather conditions influence autumn migration by mule deer in the Baggs District of Wyoming. All models included day as a variable, but the variable name was omitted for brevity. Data collected from a camera trap fixed to a highway underpass during autumn migration of 2009 and 2010. 


\begin{tabular}{|c|c|c|c|c|c|c|}
\hline Sex & Year & Model & AIC & $\triangle \mathrm{AIC}$ & $w_{\mathrm{i}}^{\mathrm{a}}$ & $\mathrm{r}^{2 \mathrm{~b}}$ \\
\hline \multirow[t]{12}{*}{ Does } & \multirow[t]{6}{*}{2009} & Min air temp, previous day & 517.73 & 0.00 & 0.83 & 0.42 \\
\hline & & Max air temp, previous day & 521.10 & 3.36 & 0.15 & 0.39 \\
\hline & & Full model & 525.76 & 8.03 & 0.02 & 0.39 \\
\hline & & Snow depth & 540.58 & 22.85 & 0.00 & 0.19 \\
\hline & & Snowfall event, previous day & 548.84 & 31.11 & 0.00 & 0.08 \\
\hline & & Precip. amount, previous day & 550.21 & 32.47 & 0.00 & 0.06 \\
\hline & \multirow[t]{6}{*}{2010} & Snow depth & 616.34 & 0.00 & 0.95 & 0.58 \\
\hline & & Min air temp, previous day & 622.12 & 5.79 & 0.05 & 0.55 \\
\hline & & Max air temp, previous day & 629.18 & 12.85 & 0.00 & 0.50 \\
\hline & & Snowfall event, previous day & 647.14 & 30.81 & 0.00 & 0.37 \\
\hline & & Precip. amount, previous day & 650.81 & 34.48 & 0.00 & 0.34 \\
\hline & & Full model & 655.28 & 38.94 & 0.00 & 0.33 \\
\hline \multirow[t]{12}{*}{ Bucks } & \multirow[t]{6}{*}{2009} & Min air temp, previous day & 329.55 & 0.00 & 0.43 & 0.26 \\
\hline & & Max air temp, previous day & 329.87 & 0.32 & 0.37 & 0.26 \\
\hline & & Snow depth & 332.39 & 2.84 & 0.10 & 0.23 \\
\hline & & Full model & 332.49 & 2.94 & 0.10 & 0.27 \\
\hline & & Snowfall event, previous day & 344.95 & 15.39 & 0.00 & 0.07 \\
\hline & & Precip. amount, previous day & 348.70 & 19.15 & 0.00 & 0.02 \\
\hline & \multirow[t]{6}{*}{2010} & Snow depth & 405.98 & 0.00 & 1.00 & 0.58 \\
\hline & & Min air temp, previous day & 426.15 & 20.17 & 0.00 & 0.46 \\
\hline & & Max air temp, previous day & 434.34 & 28.36 & 0.00 & 0.39 \\
\hline & & Full model & 446.80 & 40.82 & 0.00 & 0.32 \\
\hline & & Snowfall event, previous day & 448.51 & 42.53 & 0.00 & 0.27 \\
\hline & & Precip. amount, previous day & 452.30 & 46.31 & 0.00 & 0.23 \\
\hline
\end{tabular}

2 a Weights of evidence.

3 b Fitted model versus null model (Magee 1990). 


\section{Table 3 (on next page)}

Influence of weather on autumn migration by mule deer

Parameter estimates, standard errors, z scores, and p-values for the most-supported models examining how weather conditions influence autumn migration by mule deer in the Baggs District of Wyoming. Data collected from a camera trap fixed to a highway underpass during autumn migration of 2009 and 2010. 


\begin{tabular}{|c|c|c|c|c|c|c|}
\hline Sex & Year & Parameter & Estimate & Std. Error & $\mathrm{z}$ value & $P$-value \\
\hline \multirow{8}{*}{ Does } & 2009 & Intercept & 2.217 & 0.245 & 9.065 & $<0.001$ \\
\hline & & Min air temp, previous day & -0.206 & 0.038 & -5.364 & $<0.001$ \\
\hline & & Day & 0.011 & 0.009 & 1.193 & 0.233 \\
\hline & & Min air temp, previous day:Day & 0.004 & 0.001 & 3.719 & $<0.001$ \\
\hline & 2010 & Intercept & 1.229 & 0.253 & 4.854 & $<0.001$ \\
\hline & & Snow depth & 0.371 & 0.057 & 6.562 & $<0.001$ \\
\hline & & Day & 0.052 & 0.010 & 5.426 & $<0.001$ \\
\hline & & Snow depth:Day & -0.007 & 0.001 & -7.328 & $<0.001$ \\
\hline \multirow{8}{*}{ Bucks } & 2009 & Intercept & 1.300 & 0.272 & 4.773 & $<0.001$ \\
\hline & & Min air temp, previous day & -0.127 & 0.042 & -3.044 & 0.002 \\
\hline & & Day & -0.011 & 0.010 & -1.091 & 0.275 \\
\hline & & Min air temp, previous day:Day & 0.002 & 0.001 & 1.409 & 0.159 \\
\hline & 2010 & Intercept & 0.571 & 0.238 & 2.401 & 0.02 \\
\hline & & Snow depth & 0.402 & 0.047 & 8.487 & $<0.001$ \\
\hline & & Day & 0.026 & 0.009 & 2.945 & 0.003 \\
\hline & & Snow depth:Day & -0.007 & 0.001 & -7.910 & $<0.001$ \\
\hline
\end{tabular}




\section{1}

Study area near Baggs, Wyoming

Location of the highway underpass and fencing, and the meteorological station, near Baggs, Wyoming. During autumn, mule deer migrate from the higher elevation summer range north and east of the underpass to lower elevation winter range to the west of the highway that contains the underpass.

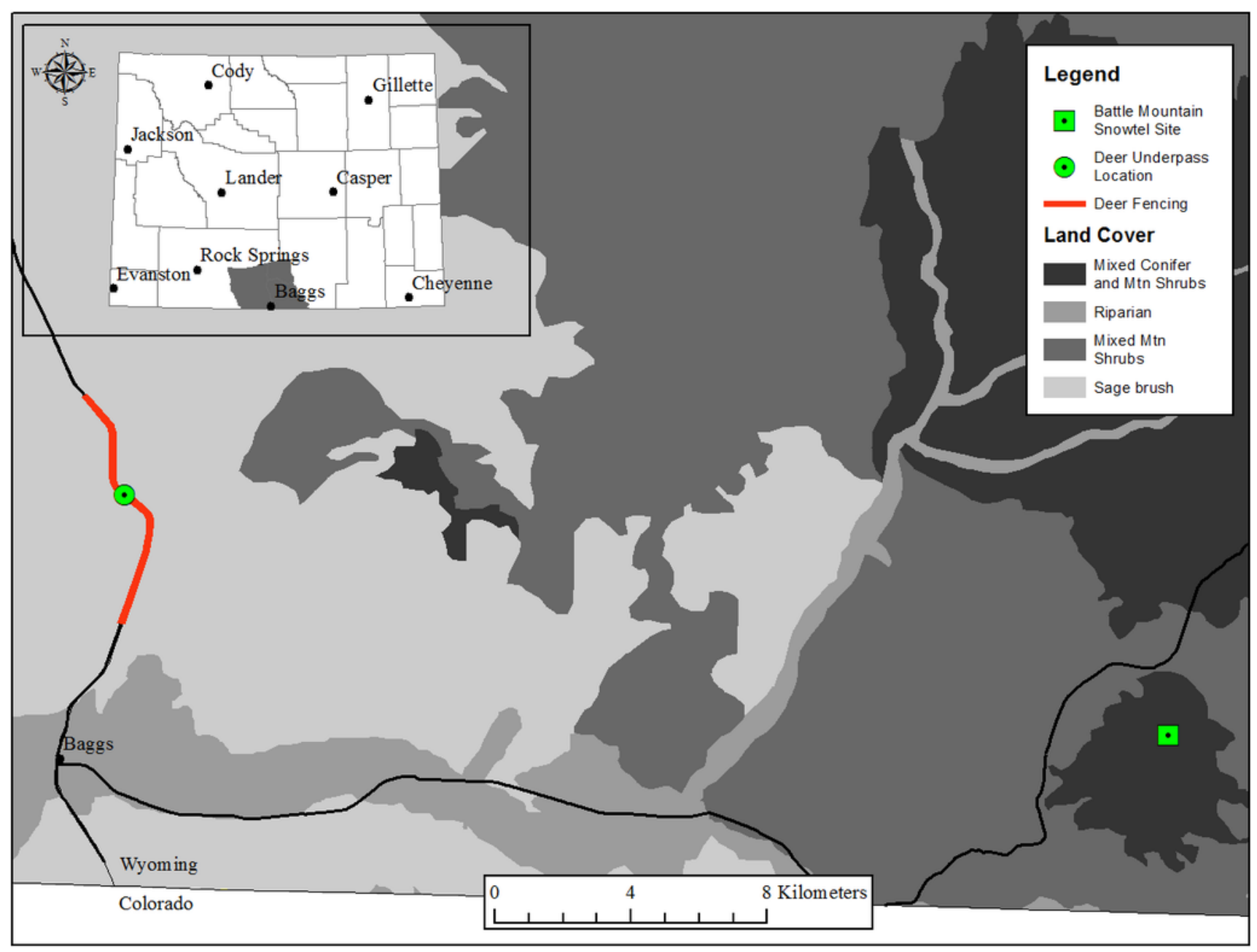


Predicted use of a highway underpass based on weather conditions

Predicted use of highway underpass during autumn migration based on most supported models of doe (A, B) and buck (C, D), over the range of weather conditions observed in 2009 (left column) and 2010 (right column) near Baggs, Wyoming.
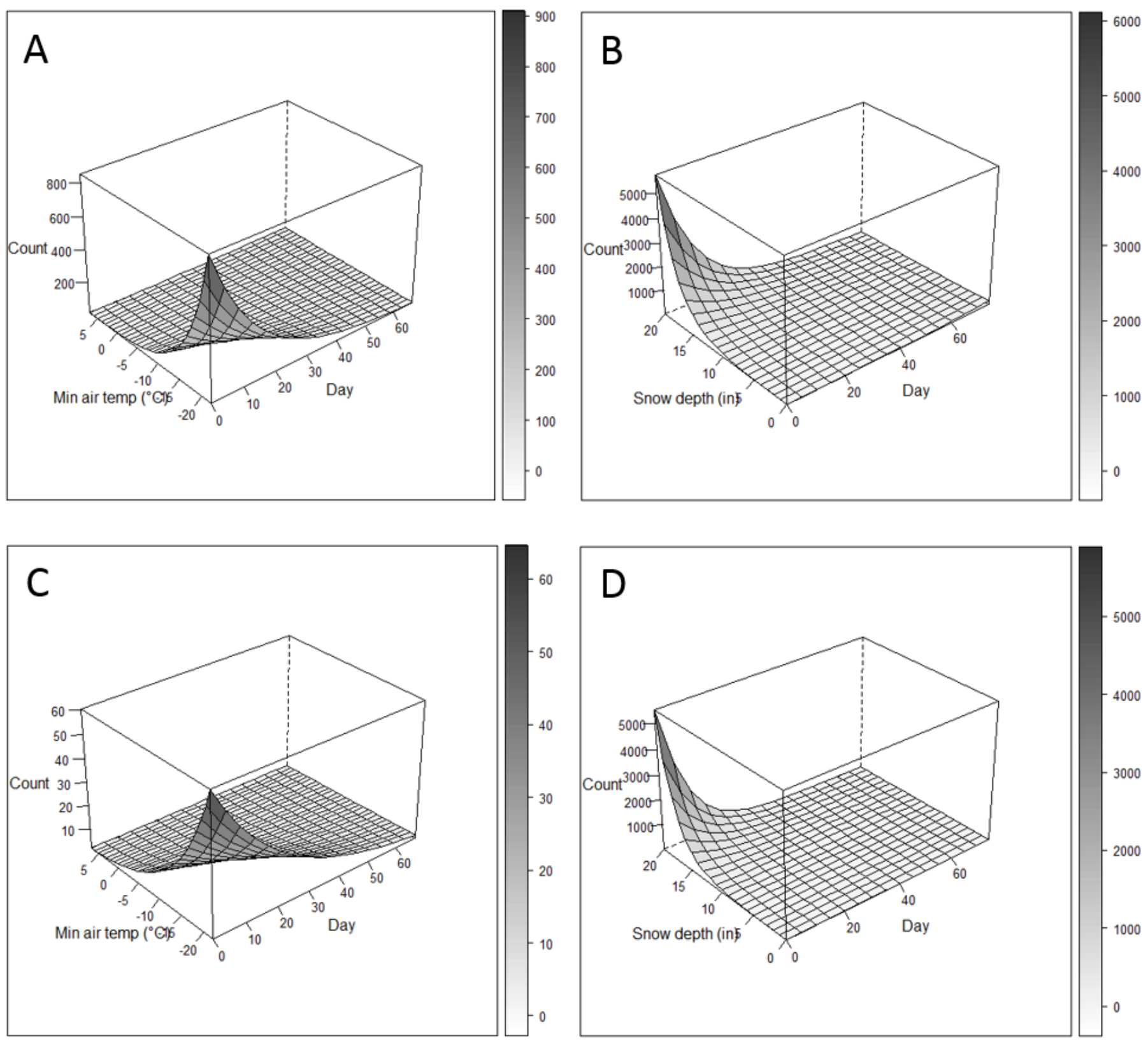